\title{
HUBUNGAN KADAR KOLESTEROL HDL SAAT MASUK RUMAH SAKIT DENGAN LUARAN KLINIS PASIEN STROKE ISKEMIK DI RS BETHESDA YOGYAKARTA
}

\author{
Florence, Rizaldy Taslim Pinzon, Esdras Ardi Pramudita \\ Fakultas Kedokteran Universitas Kristen Duta Wacana \\ Rumah Sakit Bethesda Yogyakarta \\ Korespondensi: medidoc2002@yahoo.com
}

\begin{abstract}
ABSTRAK
Pendahuluan: Stroke merupakan salah satu penyebab utama kematian dan kecacatan di dunia. Prinsip dasar terjadinya stroke adalah adanya aterosklerotrombosis. Kadar kolesterol HDL yang tinggi dapat menjadi faktor protektif terhadap stroke iskemik. Kadar kolesterol HDL yang tinggi dapat memperbaiki luaran klinis stroke iskemik. Penelitian terdahulu masih kontroversial dan memerlukan penelitian lebih lanjut.

Metode: Penelitian ini merupakan studi prognostik dengan menggunakan metode penelitian kohort retrospektif. Sampel didapatkan dari data rekam medis pasien di poliklinik saraf Rumah Sakit Bethesda Yogyakarta pada tahun 2013 sampai 2014. Data yang diperoleh kemudian dianalisis univariat, dilanjutkan dengan analisis bivariat dengan uji chi-square serta uji t-independen dan multivariat dengan uji regresi logistik.

Hasil: Dari 102 data rekam medis pasien stroke iskemik dengan onset $<24$ jam didapatkan 65 pasien laki-laki $(63,7 \%)$ dan 37 pasien perempuan (36,3\%) dengan usia terbanyak yang menderita stroke adalah usia 61-70 tahun yaitu sebanyak 36 orang (35,3\%). Pasien yang memiliki kadar kolesterol HDL yang normal saat masuk rumah sakit adalah sebanyak 53 pasien (52\%). Hasil analisis bivariat didapatkan variabel yang berhubungan signifikan dengan luaran klinis stroke iskemik adalah kolesterol total (RR: 0,273, 95\%CI: 0,106-0,700, p: 0,005), afasia (RR: 0,256, 95\%CI: 0,087-0,754,p: 0,010) dan kekuatan otot (RR: 0,344, 95\% CI: 0,137-0,863, p: 0,020). Hubungan kadar kolesterol HDL dengan luaran klinis stroke iskemik yang diukur menggunakan skor mRS didapatkan hubungan yang tidak signifikan (RR: 0,613, 95\%CI: 0,253-1,485, p: 0,276). Hasil analisis multivariat dengan regresi logistik didapatkan hasil bahwa kolesterol total dan afasia merupakan faktor independen yang mempengaruhi luaran klinis stroke iskemik.
\end{abstract}

Kesimpulan: Tidak terdapat hubungan yang signifikan antara kadar kolesterol HDL saat masuk dengan luaran klinis stroke iskemik yang diukur dengan skor mRS.

Kata Kunci: stroke iskemik, kadar kolesterol HDL, luaran klinis, modified Rankin Scale (mRS) 


\title{
ASSOCIATION BETWEEN HDL CHOLESTEROL LEVELS ON HOSPITAL ADMISSION WITH CLINICAL OUTCOMES OF ISCHEMIC STROKE IN BETHESDA HOSPITAL YOGYAKARTA
}

\author{
Florence, Rizaldy Taslim Pinzon, Esdras Ardi Pramudita \\ Medical Faculty of Duta Wacana Christian University \\ Bethesda Hospital Yogyakarta
}

Correspondence: medidoc2002@yahoo.com

\begin{abstract}
Background: Stroke is one of the major causes of death and disability in the world. The basic principle is the aterosklerotrombosis stroke. High levels of HDL cholesterol can be a protective factor against ischemic stroke because one of the functions as anti-atherogenic HDL. High levels of HDL cholesterol can improve clinical outcomes of ischemic stroke. From the previous research, it is still controversial and require further research.

Method: This study is a prognostic study using a retrospective cohort approach. Samples obtained from the medical records of patients in Bethesda Hospital Yogyakarta from 2013 until 2014. The data are analyzed using univariate, bivariate and followed by multivariate logistic regression.

Results: From 102 medical records of ischemic stroke patients with onset less than 24 hours consist of 65 male patients (63.7\%) and 37 female patients (36.3\%). The highest proportion were in range 61 until 70 years old. Patients who had normal HDL cholesterol levels at admission were 53 patients (52\%). The results of bivariate analysis variables showed that significant factors that associated with clinical outcomes of ischemic stroke is the total cholesterol (RR: 0,273, 95\% CI: 0,106 to 0,700, p: 0,005), aphasia (RR: 0,256, 95\% CI: 0,087 to 0,754, p: 0,010) and muscle strength (RR: 0,344, 95\%CI: 0,137 to 0,863, p: 0,020 ). HDL cholesterol levels relationship with clinical outcomes of ischemic stroke is measured using $m R S$ scores obtained that the correlation was not significant (RR: 0,613, 95\% CI: 0,253 to 1,485, p: 0,276). The multivariate logistic regression analysis showed that total cholesterol and aphasia were the independent factor affecting the clinical outcomes of ischemic stroke.

Conclusion: There is no significant relationship between HDL cholesterol levels at admission with ischemic stroke clinical outcomes as measured by a score of modified Rankin Scale (mRS).
\end{abstract}

Keywords: ischemic stroke, HDL cholesterol levels, clinical outcomes, modified Rankin Scale (mRS) 


\section{PENDAHULUAN}

Stroke merupakan penyakit neurologis yang serius dan paling banyak dijumpai serta angka kematian cukup tinggi. ${ }^{1}$ Diperkirakan setiap tahunnya 500.000 orang peduduk Indonesia mengalami serangan stroke, dan sekitar $25 \%$ atau 125.000 orang meninggal dan sisanya mengalami cacat berat maupun ringan. ${ }^{2}$ Menurut Riskesdas 2013, prevalensi stroke di Indonesia mengalami peningkatan dari tahun 2007 (8,3 per 1000 penduduk) hingga tahun 2013 (12,1 per 1000 penduduk) dan DI Yogyakarta menempati urutan kedua setelah Sulawesi Utara. ${ }^{3}$ Stroke iskemik adalah sindrom neurologi yang merupakan ancaman terbesar karena dapat menimbulkan kecacatan. ${ }^{4}$ Data register stroke RS Bethesda Yogyakarta tahun 2011-2013 menunjukan jumlah penderita stroke 2460 pasien dan paling banyak adalah stroke iskemik yaitu sebesar 74,67 \%. ${ }^{5}$ Stroke iskemik terjadi karena aliran darah ke otak berkurang, akibat adanya sumbatan karena aterosklerosis. ${ }^{6}$

Salah satu upaya mencegah stroke adalah meningkatkan kadar HDL, dan kadar HDL yang rendah merupakan salah satu faktor risiko pada stroke iskemik. ${ }^{7,8}$ Beberapa penelitian menyebutkan bahwa kadar HDL memiliki pengaruh terhadap luaran klinis stroke iskemik namun hasil ini masih menimbulkan perdebatan, karena terdapat hasil penelitian yang berbeda-beda. Penelitian sebelumnya menyatakan pasien dengan kadar HDL rendah $(\leq 35 \mathrm{mg} / \mathrm{dL})$ memiliki luaran klinis yang buruk. ${ }^{9}$ Penelitian yang lain menyatakan bahwa pasien yang memiliki kadar HDL yang rendah memiliki luaran klinis yang baik. Hubungan antara kadar kolesterol HDL dan luaran klinis pasien stroke iskemik masih menjadi perdebatan dan memerlukan penelitian lebih lanjut. Tujuan dari penelitian ini adalah untuk mengetahui hubungan antara kadar kolesterol HDL saat masuk rumah sakit dengan luaran klinis pasien stroke iskemik.

\section{METODE PENELITIAN}

Penelitian ini merupakan studi prognostik dengan metode kohort retrospektif dengan menggunakan data sekunder yaitu data rekam medis pasien periode tahun 2013 hingga tahun 2014. Sampel penelitian adalah pasien stroke iskemik serangan pertama di RS Bethesda Yogyakarta yang didiagnosis dengan CT (computed tomography) scan kepala, onset kurang dari 24 jam dan bukan pasien yang pulang paksa. Pengumpulan sampel dilakukan dengan teknik pengambilan sampel konsekutif dan didapatkan 102 data dari 308 data rekam medis pasien stroke iskemik tahun 2013 hingga tahun 2014. Variabel bebas adalah kadar kolesterol HDL dan variabel tergantung adalah luaran klinis stroke iskemik.

Data diolah melalui analisis deskriptif dan analisis statistik secara komputerisasi. Analisis deskriptif meliputi data karakteristik dasar seluruh pasien penelitian dengan analisis univariat. Analisis statistik meliputi Chi-Square Test untuk analasis bivariat untuk menilai hubungan variabel penelitian dengan variabel tergantung, dan uji homogenitas untuk menilai hubungan variabel perancu dengan variabel bebas, Kolmogorov-Smirnov Test dan Independent t-test untuk menilai hubungan kadar kolesterol HDL dengan luaran klinis stroke iskemik, serta analisis multivariat menggunakan analisis regresi logistik. 


\section{HASIL PENELITIAN}

Tabel 1. Data karakteristik dasar seluruh pasien penelitian

\begin{tabular}{|c|c|c|}
\hline Karakteristik Pasien & $\mathrm{n}=102$ & $\%$ \\
\hline \multicolumn{3}{|l|}{ Usia } \\
\hline $41-50$ tahun & 11 & 10,8 \\
\hline 51-60 tahun & 34 & 33,3 \\
\hline $61-70$ tahun & 36 & 35,3 \\
\hline$>70$ tahun & 21 & 20,6 \\
\hline \multicolumn{3}{|l|}{ Jenis Kelamin } \\
\hline Laki-laki & 65 & 63,7 \\
\hline Perempuan & 37 & 36,3 \\
\hline \multicolumn{3}{|l|}{ Onset } \\
\hline$<3$ jam & 14 & 13,7 \\
\hline 3-6 jam & 33 & 32,4 \\
\hline 6-12 jam & 43 & 42,2 \\
\hline $12-24$ jam & 12 & 11,8 \\
\hline \multicolumn{3}{|l|}{ Tingkat kesadaran } \\
\hline Compos mentis & 89 & 87,3 \\
\hline Somnolen & 8 & 7,8 \\
\hline Stupor & 5 & 4,9 \\
\hline \multicolumn{3}{|c|}{ Kadar asam urat saat masuk rumah sakit (mg/dL) } \\
\hline Normal $(\mathrm{Lk} \leq 7,00, \operatorname{Pr} \leq 5,70)$ & 64 & 62,7 \\
\hline Tinggi $(\mathrm{Lk}>7,00, \mathrm{Pr}>5,70)$ & 38 & 37,3 \\
\hline \multicolumn{3}{|c|}{ Kadar gula darah saat masuk rumah sakit (mg/dL) } \\
\hline Normoglikemia $(\leq 140)$ & 65 & 63,7 \\
\hline Hiperglikemia (>140) & 37 & 36,3 \\
\hline \multicolumn{3}{|l|}{ Kadar LDL saat masuk rumah sakit (mg/dL) } \\
\hline Normal $(<160)$ & 66 & 64,7 \\
\hline Tinggi $(\geq 160)$ & 36 & 35,5 \\
\hline \multicolumn{3}{|l|}{ Kadar HDL saat masuk rumah sakit (mg/dL) } \\
\hline Normal (Lk $\geq 40, \operatorname{Pr} \geq 50)$ & 53 & 52,0 \\
\hline Rendah (Lk <40, Pr >50) & 49 & 48,0 \\
\hline \multicolumn{3}{|c|}{ Kadar trigliserid saat masuk rumah sakit (mg/dL) } \\
\hline Normal $(<200)$ & 59 & 57,8 \\
\hline Tinggi $(\geq 200)$ & 43 & 42,2 \\
\hline \multicolumn{3}{|c|}{ Tekanan darah sistolik saat masuk rumah sakit (mmHg) } \\
\hline Normal $(\leq 120)$ & 9 & 8,8 \\
\hline Tinggi (>120) & 93 & 91,2 \\
\hline \multicolumn{3}{|c|}{ Tekanan darahdiastolik saat masuk rumah sakit (mmHg) } \\
\hline Normal $(\leq 80)$ & 25 & 24,5 \\
\hline Tinggi (>800) & 77 & 75,5 \\
\hline \multicolumn{3}{|c|}{ Kadar leukosit saat masuk rumah sakit (x106/L) } \\
\hline Normal $(\leq 11)$ & 83 & 81,4 \\
\hline Tinggi $(>11)$ & 19 & 18,6 \\
\hline \multicolumn{3}{|c|}{ Kadar kolesterol total saat masuk rumah sakit $(\mathrm{mg} / \mathrm{dL})$} \\
\hline Normal $(<200)$ & 50 & 49,0 \\
\hline Tinggi ( $\geq 200)$ & 52 & 51,0 \\
\hline \multicolumn{3}{|l|}{ Atrial Fibrilasi } \\
\hline $\mathrm{Ya}$ & 2 & 2,0 \\
\hline Tidak & 100 & 98,0 \\
\hline
\end{tabular}


Riwayat diabetes mellitus

Ya

Tidak

0

102

0

00,0

Riwayat dislipidemia

Ya

53

52,0

Tidak

49

48,0

Riwayat hipertensi

Ya

50

49,0

Tidak

52

51,0

Kekuatan Otot

0-tidak terdapat kontraksi yang terlihat

1-tampak ada sedikit kontraksi

2-gerakan aktif dengan penghilangan gravitas

3-gerakan aktif terhadap gravitasi

4-gerakan aktif terhadap gravitasi dan beberapa tahanan

5-gerakan aktif terhadap tahanan penuh

Kelemahan sisi

Kanan

Kiri

Afasia

Ya

Tidak

Komplikasi

Ya

Tidak

Klasifikasi mRS

Baik $(\leq 2)$

Buruk (>2)

$\begin{array}{cc}5 & 4,9 \\ 19 & 18,6 \\ 6 & 5,9 \\ 13 & 12,7 \\ 37 & 36,3 \\ 22 & 21,6\end{array}$

50

49,0

51,0

16,7

$85 \quad 83,3$

$44 \quad 43,1$

$58 \quad 56,9$

$74 \quad 72,5$

$28 \quad 27,5$
Analisis deskriptif yang dilakukan pada seluruh pasien penelitian memberikan gambaran seperti pada tabel 1. Seratus dua pasien yang memenuhi kriteria inklusi dan eksklusimasukdalam penelitianini,yang terdiri dari 65 pasien laki-laki $(63,7 \%)$ dan 37 pasien perempuan $(36,3 \%)$. Rentang usia terbanyak yang menderita stroke adalah usia 61-70 tahun yaitu sebanyak 36 orang (35,3\%). Onset masuk RS pasien tertinggi yaitu pada waktu 6-12 jam (42,2\%). Berdasarkan hasil pada tabel 1, didapatkan 49 pasien memiliki kadar HDL yang rendah (48\%) dan 53 pasien memiliki kadar HDL yang normal (52\%). Kadar gula darah, kadar asam urat, HDL, LDL, leukosit, dan trigliserid dari tabel tersebut rata-rata memiliki nilai normal sedangkan kadar koleseterol total, tekanan darah sistolik, dan tekanan darah diastolik rata-rata memiliki nilai tinggi atau di atas normal. Tabel di atas juga memperlihatkan $2 \%$ pasien memiliki riwayat atrial fibrilasi, $50 \%$ pasien memiliki riwayat hipertensi, 53\% pasien memiliki riwayat dislipidemia, $17 \%$ pasien memiliki riwayat afasia, dan tidak ada yang memiliki riwayat diabetes mellitus $(0 \%)$. Kekuatan otot dengan kategori gerakan aktif terhadap gravitasi dan beberapa tahanan memiliki jumlah paling tinggi yang ditemukan pada 37 pasien (36\%). Pasien yang memiliki komplikasi sebesar 44 pasien (43,1\%), dan yang memiliki luaran klinis baik $(\leq 2)$ yang diukur dengan skala MRS sebesar 74 pasien $(72,5 \%)$. 
Tabel 2. Analisis bivariat variabel penelitian dan tergantung

\begin{tabular}{|c|c|c|c|c|c|}
\hline Variabel & $\begin{array}{c}\mathrm{mRS} \leq 2 \\
(\mathrm{n}=74)\end{array}$ & $\begin{array}{c}m R S>2 \\
(n=28)\end{array}$ & $\mathbf{R R}$ & 95\% IK & Nilai p \\
\hline \multicolumn{6}{|l|}{ Jenis Kelamin } \\
\hline Laki-laki & $47(46,1 \%)$ & $18(17,6 \%)$ & 0,967 & $0,391-2,394$ & 0,942 \\
\hline Perempuan & $27(26,5 \%)$ & $10(9,8 \%)$ & & & \\
\hline \multicolumn{6}{|l|}{ Usia } \\
\hline 41-50 tahun & $8(7,8 \%)$ & $3(2,9 \%)$ & & & 0,674 \\
\hline 51-60 tahun & $26(25,5 \%)$ & $8(7,8 \%)$ & 0,609 & $0,124-2,996$ & 0,542 \\
\hline $61-70$ tahun & $27(26,5 \%)$ & $9(8,8 \%)$ & 0,500 & $0,153-1,635$ & 0,252 \\
\hline$>70$ tahun & 13 (12,7\%) & $8(7,8 \%)$ & 0,542 & $0,170-1,727$ & 0,300 \\
\hline \multicolumn{6}{|l|}{ Onset Stroke } \\
\hline$<3$ jam & $12(11,8 \%)$ & $2(2,0 \%)$ & & & 0,181 \\
\hline 3-6 jam & $24(23,5 \%)$ & $9(8,8 \%)$ & 1,833 & $0,145-23-154$ & 0,639 \\
\hline 6-12 jam & $27(26,5 \%)$ & $16(15,7 \%)$ & 4,125 & $0,464-36,702$ & 0,204 \\
\hline 12-24 jam & $11(10,8 \%)$ & $1(1,0 \%)$ & 6,519 & $0,768-55,319$ & 0,086 \\
\hline \multicolumn{6}{|l|}{ Tingkat kesadaran } \\
\hline Compos mentis & $65(63,7 \%)$ & $24(23,5 \%)$ & & & 0,811 \\
\hline Somnolen & $6(5,9 \%)$ & $2(2,0 \%)$ & 0,554 & $0,087-3,520$ & 0,531 \\
\hline Stupor & $3(2,9 \%)$ & $2(2,0 \%)$ & 0,500 & $0,045-5,514$ & 0,571 \\
\hline \multicolumn{6}{|l|}{ Kadar asam urat (mg/dL) } \\
\hline Normal $(\mathrm{L} \leq 7,0$ Pr $\leq 5,7)$ & $45(44,1 \%)$ & $19(18,6 \%)$ & & & 0,511 \\
\hline Tinggi $(\mathrm{L}>7,2 \mathrm{Pr}>5,7)$ & $29(28,4 \%)$ & $9(8,8 \%)$ & 0,735 & $0,293-1,845$ & \\
\hline \multicolumn{6}{|l|}{ Kadar gula darah $(\mathrm{mg} / \mathrm{dL})$} \\
\hline Normal $(\leq 140)$ & $48(47,1 \%)$ & 17 (16,7\%) & & & 0,697 \\
\hline Tinggi (>140) & $26(25,5 \%)$ & $11(10,8 \%)$ & 1,195 & $0,488-2,927$ & \\
\hline \multicolumn{6}{|l|}{$\mathrm{LDL}(\mathrm{mg} / \mathrm{dL})$} \\
\hline Normal $(<160)$ & $46(45,1 \%)$ & $20(19,6 \%)$ & & & 0,382 \\
\hline Tinggi ( $\geq 160)$ & $28(27,5 \%)$ & $8(7,8 \%)$ & 0,657 & $0,255-1,691$ & \\
\hline \multicolumn{6}{|l|}{$\mathrm{HDL}(\mathrm{mg} / \mathrm{dL})$} \\
\hline Normal (L $\geq 40$ Pr $\geq 50)$ & $36(35,3 \%)$ & 17 (16,7\%) & & & 0,276 \\
\hline Rendah (L<40 Pr>50) & $38(37,3 \%)$ & $11(10,8 \%)$ & 0,613 & $0,253-1,485$ & \\
\hline \multicolumn{6}{|l|}{ Trigliserid (mg/dL) } \\
\hline Normal $(<200)$ & $41(40,2 \%)$ & $18(17,6 \%)$ & & & 0,418 \\
\hline Tinggi ( $\geq 200)$ & $33(32,4 \%)$ & $10(9,8 \%)$ & 0,690 & $0,281-1,696$ & \\
\hline \multicolumn{6}{|c|}{ Tekanan darah sistol (mmHg) } \\
\hline Normal $(\leq 120)$ & $7(6,9 \%)$ & $2(2,0 \%)$ & & & 0,713 \\
\hline Tinggi (>120) & $67(65,7 \%)$ & $26(25,5 \%)$ & 1,358 & $0,265-6,970$ & \\
\hline \multicolumn{6}{|c|}{ Tekanan darah diastol (mmHg) } \\
\hline Normal $(\leq 80)$ & $17(16,7 \%)$ & $8(7,8 \%)$ & & & 0,557 \\
\hline Tinggi (>80) & $57(55,9 \%)$ & $20(19,6 \%)$ & 0,746 & $0,297-1,992$ & \\
\hline \multicolumn{6}{|l|}{ Leukosit $\left(\mathrm{x} 10^{6} / \mathrm{L}\right)$} \\
\hline Normal $(\leq 11)$ & $59(57,8 \%)$ & $24(23,5 \%)$ & & & 0,488 \\
\hline Tinggi $(>11)$ & $15(14,7 \%)$ & $4(3,9 \%)$ & 0,656 & $0,197-2,178$ & \\
\hline \multicolumn{6}{|l|}{ Kolesterol total (mg/dL) } \\
\hline Normal $(<200)$ & $30(29,4 \%)$ & $20(19,6 \%)$ & & & 0,005 \\
\hline Tinggi $(\geq 200)$ & $44(43,1 \%)$ & $8(7,8 \%)$ & 0,273 & $0,106-0,700$ & \\
\hline \multicolumn{6}{|l|}{ Atrial fibrilsi } \\
\hline $\mathrm{Ya}$ & $2(2,0 \%)$ & $0(0 \%)$ & 1,389 & $1,229-1,569$ & 0,380 \\
\hline Tidak & $72(70,6 \%)$ & $28(27,5 \%)$ & & & \\
\hline \multicolumn{6}{|l|}{ Riwayat Hipertensi } \\
\hline $\mathrm{Ya}$ & $36(35,3 \%)$ & $14(13,7 \%)$ & 0,947 & $0,397-2,261$ & 0,903 \\
\hline Tidak & $38(37,3 \%)$ & $14(13,7 \%)$ & & & \\
\hline
\end{tabular}




\begin{tabular}{|c|c|c|c|c|c|}
\hline \multicolumn{6}{|c|}{ Riwayat Dislipidemia } \\
\hline $\mathrm{Ya}$ & $38(37,3 \%)$ & $15(14,7 \%)$ & 0,915 & $0,383-2,187$ & 0,841 \\
\hline Tidak & $36(35,3 \%)$ & $13(12,7 \%)$ & & & \\
\hline \multicolumn{6}{|l|}{ Kekuatan otot } \\
\hline Buruk (<3) & $17(16,7 \%$ & $13(12,7 \%)$ & 0,344 & $0,137-0,863$ & 0,020 \\
\hline Baik ( $\geq 3)$ & 57 (55,9\%) & $15(14,7 \%)$ & & & \\
\hline \multicolumn{6}{|l|}{ Kelemahan sisi } \\
\hline Kanan & $36(35,3 \%)$ & $14(13,7 \%)$ & & & 0,903 \\
\hline Kiri & $38(37,3 \%)$ & $14(13,7 \%)$ & 0,947 & $0,397-2,261$ & \\
\hline \multicolumn{6}{|l|}{ Afasia } \\
\hline $\mathrm{Ya}$ & $8(7,8 \%)$ & $9(8,8 \%)$ & 0,256 & $0,087-0,754$ & 0,010 \\
\hline Tidak & $66(64 \%)$ & $19(18,6 \%)$ & & & \\
\hline \multicolumn{6}{|l|}{ Komplikasi } \\
\hline $\mathrm{Ya}$ & $33(32,4 \%)$ & $11(10,8 \%)$ & 1,244 & $0,513-3,017$ & 0,629 \\
\hline Tidak & $41(40,2 \%)$ & $17(16,7 \%)$ & & & \\
\hline
\end{tabular}

Berdasarkan hasil analisis bivariat pada tabel 2, terlihat bahwa variabel yang memiliki hubungan yang signifikan dengan disabilitas (luaran klinis) pasien stroke iskemik akut yang dinilai dengan skala Rankin yang dimodifikasi (nilai $p<0,05)$ adalah kadar kolesterol total, afasia dan kekuatan otot.

Tabel 3. Hubungan kadar kolesterol HDL dengan luaran klinis stroke iskemik

\begin{tabular}{|c|c|c|c|c|}
\hline Variabel & $\begin{array}{c}\text { MRS } \leq 2 \\
(\text { Mean } \pm \text { SD) }\end{array}$ & $\begin{array}{c}\text { MRS }>2 \\
(\text { mean } \pm S D)\end{array}$ & $\begin{array}{c}\text { Kolmogorov-Smirnov } \\
\text { Test (Nilai p) }\end{array}$ & $\begin{array}{l}\text { Independent } \\
\text { t-test (nilai p) }\end{array}$ \\
\hline $\begin{array}{l}\text { Kadar kolesterol } \\
\text { HDL }\end{array}$ & $43,99 \pm 11,90$ & $44,82 \pm 9,02$ & 0,058 & 0,321 \\
\hline
\end{tabular}

Independent t-test digunakan untuk menguji apakah terdapat hubungan antara kadar kolesterol HDL dengan luaran klinis stroke iskemik, dan syarat dapat digunakan uji ini adalah data harus berdistribusi normal sehingga digunakan Kolmogrov-Smirnov Test. Hasil Kolmogrov-Smirnov Test menunjukan data berdistribusi normal (nilai $\mathrm{p}>\mathrm{a}$ ), sehingga dapat dilakukan Independent t-test dan hasilnya menunjukan tidak ada hubungan yang signifikan antara kadar kolesterol HDL saat masuk RS dengan luaran klinis stroke iskemik.

Tabel 4. Analisis multivariat hubungan antara variabel kolesterol total, afasia dan kekuatan otot terhadap luaran klinis stroke iskemik menggunakan skala MRS

\begin{tabular}{lccc}
\hline \multicolumn{1}{c}{ Variabel } & Nilai $\mathbf{~ p}$ & RR & CI (95\%) \\
\hline Kolesterol total (tinggi) & 0,010 & 3,584 & $1,359-9,451$ \\
Afasia & 0,021 & 3,779 & $1,218-11,723$ \\
Kekuatan otot (buruk) & 0,107 & 2,254 & $0,838-6,062$ \\
\hline
\end{tabular}

Analisis multivariat dengan regresi logistik menunjukan terdapat dua variabel yang memiliki hubungan signifikan dengan luaran klinis stroke iskemik $(p<0,05)$. Kedua variabel tersebut adalah kolesterol total (RR: 
3,584, 95\%IK: 1,359-9,451, p: 0,010) dan afasia (RR: 3,779, 95\%IK: 1,21811,723, p: 0,021).

\section{PEMBAHASAN}

Hasil analisis menunjukan tidak terdapat hubungan yang signifikan antara kadar kolesterol HDL saat masuk rumah sakit dengan luaran klinis pasien stroke iskemik yang dinilai dengan skala Rankin yang dimodifikasi, sehingga hasilnya tidak sesuai dengan hipotesis (RR: 0,613, 95\%, IK: 0,253-1,485, p: 0,276). Hasil ini sesuai dengan hasil penelitian yang dilakukan oleh Pamungkas (2013) yang mengatakan tidak terdapat hubungan yang signifikan antara hubungan kadar HDL saat masuk Rumah Sakit dengan gangguan kemampuan ADL yang dinilai dengan indeks Barthel pada pasien stroke iskemik di RSUP Dr. Sardjito, namun hal ini tidak sesuai dengan penelitian yang dilakukan oleh Lipska et al (2007) yang menunjukan bahwa kadar HDL yang rendah merupakan faktor independen untuk luaran stroke iskemik. ${ }^{10,11}$ Hal ini dapat disebabkan oleh karena metode penelitian yang digunakan yaitu kohort retrospektif yang berbeda dari penelitian-penelitian sebelumnya, yang menggunakan metode kohort dengan follow up langsung ke pasien dalam kurun waktu yang lama (bertahun-tahun) untuk mendapatkan data perkembangan langsung dari pasien, sedangkan dalam penelitian ini data diambil dari rekam medis yang diamati dalam kurun waktu tertentu.

Hasil penelitian menunjukan 53 pasien memiliki kadar HDL normal dan sebanyak 36 pasien $(35,3 \%)$ memiliki luaran klinis baik. Hasil tersebut sesuai dengan penelitian Yi-Heng Li et al (2013), yang menyatakan bahwa pasien dengan kadar kolesterol HDL yang rendah ( $\leq 35 \mathrm{mg} / \mathrm{dL})$ memiliki hubungan dengan tingginya tingkat keparahan stroke yang ditandai dan buruknya luaran klinis yang dilihat dari tingginya skala Rankin yang dimodifikasi yang merupakan skala ukur untuk menilai luaran klinis pada pasien stroke. ${ }^{9}$ Hasil penelitian tersebut juga didukung oleh Sohail et al (2013) yang menyatakan pasien stroke dengan kadar HDL yang rendah memiliki keparahan stroke yang besar dan luaran klinis yang buruk, pernyataan tersebut bertentangan dengan penelitian yang dilakukan oleh Tian et al (2014) yang menyatakan pasien dengan kadar HDL yang normal memiliki luaran klinis yang buruk dibandingkan dengan pasien dengan kadar HDL yang yang abnormal, karena partikel HDL dapat menjadi proinflamasi dan pro-aterogenik pada fase akut stroke. ${ }^{12,13}$

Nilai RR (risiko relative) kolesterol total adalah 3,584 hal ini bermakna bahwa pasien stroke iskemik dengan kolesterol total yang tinggi ( $\geq 200 \mathrm{mg} / \mathrm{dL}$ ) memiliki risiko 3,5 kali memiliki luaran klinis yang buruk dibandingkan dengan mereka yang memiliki kadar kolesterol total yang normal. Hasil tersebut sesuai dengan penelitian yang dilakukan oleh Tian et al (2014) yang menyatakan bahwa kadar kolesterol total yang tinggi memperburuk luaran klinis stroke, karena oksidasi dari kolesterol dapat menginisiasi proses inflamasi dan pembentukan plak pada dinding pembuluh darah sehingga dapat menghambat aliran darah pada arteri. ${ }^{13}$ Hasil penelitian tersebut bertentangan dengan penelitian yang dilakukan oleh Olsen et al (2007) yang menyatakan kadar kolesterol total yang tinggi berhubungan dengan berkurangnya keparahan stroke dan menghasilkan luaran klinis yang lebih baik karena dipengaruhi oleh efek protektif penggunaan statin pada fase akut stroke. ${ }^{14}$ Hasil tersebut didukung oleh penelitian Muhammad 
et al (2014) yang menyatakan pasien dengan kadar kolesterol total yang tinggi memiliki luaran klinis yang baik (tingginya skor Barthel Index), karena kolesterol berfungsi sebagai buffer untuk menetralisir radikal bebas dan mencegah kerusakasan jaringan sel saraf. ${ }^{15}$

Nilai RR (risiko relatif) pada afasia adalah 3,779 $(\mathrm{R} R>1)$ yang bermakna bahwa pasien stroke iskemik dengan afasia memiliki risiko 3,8 kali memiliki luaran klinis yang buruk dibanding dengan mereka yang tidak afasia. Afasia adalah gangguan bahasa yang merupakan hasil dari kerusakan bagian di otak yang bertanggung jawab terhadap bahasa, yang paling banyak disebabkan oleh stroke. ${ }^{16}$ Afasia pada pasien stroke iskemik berhubungan dengan peningkatan kematian, mengurangi tingkat pemulihan kemampuan fungsional dan mengurangi kapasitas kerja. ${ }^{17}$ Kemampuan berbahasa menjadi indikator penting untuk kemandirian aktivitas fungsional dimana semakin berat gangguan afasia sensorik yang diderita maka semakin sulit untuk pasien mencapai kemandirian dalam aktivitasnya sehari-hari. ${ }^{18}$

Keterbatasan penelitian ini adalah karena menggunakan desain penelitian kohort retrospektif dengan menggunakan data sekunder yaitu rekam medis. Pada desain penelitian kohort retrospektif terdapat kelemahan yang sulit dihindari karena peneliti tidak mampu mengontrol keadaan dan kualitas pengukuran yang dilakukan oleh orang lain pada masa lalu karena menggunakan data sekunder. Penelitian yang semata-mata mengandalkan data sekunder dari rekam medis selalu memiliki kekurangan karena peneliti tidak mampu mengontrol kualitas pengukuran terhadap kadar kolesterol HDL saat masuk RS dan luaran klinis stroke yang dilakukan oleh orang lain pada masa lalu.

\section{KESIMPULAN}

Tidak terdapat hubungan yang signifikan antara kadar kolesterol HDL saat masuk RS dengan luaran klinis pasien stroke iskemik akut yang diukur dengan skala Rankin yang dimodifikasi.

\section{DAFTAR PUSTAKA}

1. Goldszmidt, A.J. \& Caplan, L.R. Esensial Stroke. Jakarta : EGC; 2013

2. Ovina, Y., Riowastu, I. \& Yuwono. Hubungan Pola Makan, Olahraga, dan Merokok terhadap Prevalensi Penyakit Stroke Non Hemoragik. Online-journal 2013;09;2. [Online] Available from : http://onlinejournal.unja.ac.id[Accessed 19/09/2014]

3. Indonesia. Badan Penelitian dan Pengembangan Kesehatan, Kementerian Kesehatan RI. Riset Kesehatan Dasar (Riskesdas 2013). Jakarta; 2013

4. American Stroke Association/ American Hearth Association. Ischemic Strokes (Clots). 2013. [Online] Available from : http://www.strokeassociation.org/STROKEORG/ AboutStroke/TypesofStroke/IschemicClots/Ischemic-Strokes-Clots_ UCM_310939_Article.jsp [Accessed 19/09/2014]

5. Pinzon, R. Profil Stroke : Gambaran Tentang Pola Demografi, Faktor Resiko, Gejala Klinik, dan Luaran Klinis Pasien Stroke. Yogyakarta: BETHA GRAFIKA; 2014

6. Kowalak, J.P., Welsh, W. \& Mayer, B. Buku Ajar Patofisiologi. Jakarta: EGC; 2011

7. Harsono. Kapita Selekta Neurologi Edisi Kedua. Yogyakarta: Gadjah Mada University Press. 
8. Alway, D. \& Cole, J.W. Esensial Stroke untuk Layanan Primer. Jakarta: EGC; 2012

9. Li, Y.H., Yeh, P.S., Yang, C.M., Chen P.S., Lin, H.J., et al. (2013) Low Levels of High-Density Lipoprotein Cholesterol in Patients with Atherosclerotic Stroke: A Prospective Cohort Study. JACC Journals 2013 ; 61: abstract. [Online] Available from : http://content.onlinejacc.org/ article [Accessed 09/08/2014]

10. Pamungkas, S.C. Hubungan Antara Kadar HDL Kolesterol Saat Masuk dengan Gangguan Kemampuan ADL yang Dinilai dengan Indeks Barthel Pada Pasien Stroke Iskemik di RSUP dr. Sardjito. [Skripsi] Yogyakarta: Universitas Gadjah Mada; 2013

11. Lipska, K., Sylaja, P.N., Sarma, P.S., Thankappan, K.R., Kutty, V.R., et al. Risk factors for acute ischaemic stroke in young adults in South. $J$ Neurosurgery Psychiatry 2007; 78: 959-963. [Online] Available from: http://www.ncbi.nlm.nih. gov / pmc/articles / PMC2117871/ [Accessed 08/05/2015]

12. Sohail, A. Khatri, I.A., Mehboob, N. Effect of dyslipidemia ob severity and outcome of stroke using mRS scores in Nothern Pakistani population. RMJ 2013; 38: 345-350.

13. Tian, X., Tao, Z.J., Mei, Y., Huan, Z., Qing, L.W., et al. Dyslipidemia and Outcome in Patients with Acute Ischemic Stroke. Bes Journal 2014; 27: 106-110. [Online] Available from : http://www.besjournal.com [Accessed 09/08/2014]

14. Olsen, T.S., Christensen, R.H.B., Kammersgaard, L.P., Andersen,
K.K. Higher Total Serum Cholesterol Levels Are Are Associated With Less Severe Strokes and Lower All-Cause Mortality Ten-Year Follow-Up of Ischemic Strokes in the Copenhagen Stroke Study. AHA J 2007; 38: 2646-2651. [Online] Available from : http://stroke.ahajournals. org/content/38/10/2646.full.pdf [Accessed 08/05/2015]

15. Muhammad, D., Javed, M., Sheikh, G.A. (2015) Acute Ischemic Stroke; Correlation Between Higher Total Cholesterol Level and High Barthel Index Score in Patients. The Pofessional Medical J; 22: 276-280. [Online] Available from: http:// www.theprofesional.com/article/ vol.\%2022\%20no.\%2003/Prof2654.pdf [Accessed 08/05/2015]

16. The Internet Stroke Center. What is Aphasia?. 2015. [Online] Available from: http:/ /www.strokecenter.org/ patients / caregiver-and-patientresources / aphasia-information / [Accessed 08/05/2015]

17. Kadojic, D., Bijelic, B.R., Radanovic, R., Porobic, M., Rimac, J., et al. Aphasia in patients with ischemic stroke. Acta Clin Croat 2012; 51: 221-225. [Online] Available from: http: / / www.ncbi.nlm.nih.gov / pubmed/23115946 [Accessed 08/05/2015]

18. Wirawan, R.P. Rehabilitasi Stroke pada Pelayanan Kesehatan Primer. Digital journals 2009; 59: 61-71. [Online] Available from: http: / / indonesia.digitaljournals. org/index.php/idnmed/article / download/626/614 [Accessed 08/05/2015] 